\title{
Launois-Bensaude syndrome after liver transplantation
}

\author{
Jolan Dupont resident, internal medicine ${ }^{1}$, Bart Van der Schueren professor of endocrinology ${ }^{12}$, \\ Ann Mertens professor of endocrinology ${ }^{1}$
}

${ }^{1}$ University Hospitals of Leuven, Leuven, Belgium; ${ }^{2}$ Department of Chronic Diseases, Metabolism and Aging (CHROMETA), University of Leuven, Leuven, Belgium

A 66 year old man presented with several subcutaneous fat deposits, which had developed three months after liver transplantation for alcoholic cirrhosis. Clinical examination showed painless symmetric soft masses on the shoulders, upper arms, upper legs, and neck, giving the patient a pseudo-athletic appearance (fig 1). Biochemical analysis showed a normal lipid profile. Magnetic resonance imaging confirmed diffuse lobulated and symmetric lipomatosis (fig 2).
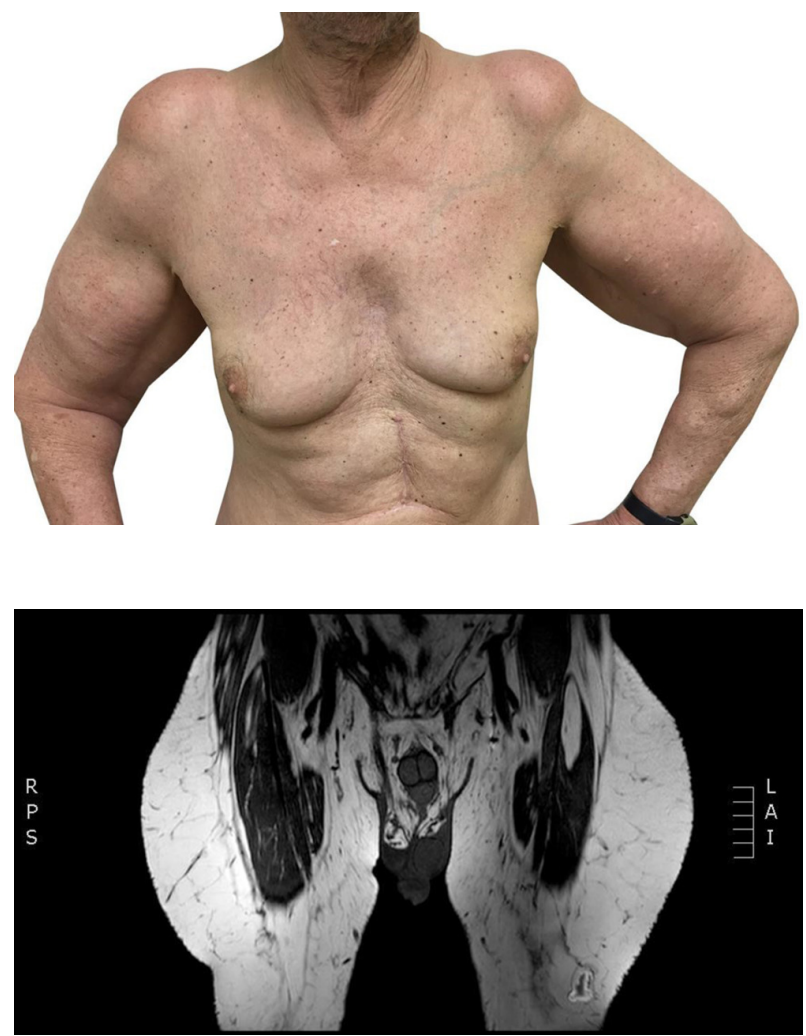

Launois-Bensaude syndrome, or Madelung's disease, is a rare benign symmetric lipomatosis. The cause is unknown, but alcoholism or liver dysfunction are observed in up to $90 \%$ of patients. ${ }^{1}$ The condition has not been shown to spontaneously regress. Treatment, if required, is surgical-lipectomy, injection lipolysis, or liposuction of the lipomas - and is mostly performed for functional, cosmetic, or psychological reasons. Rarely, intervention is required to relieve aerodigestive tract obstruction. Differential diagnoses to consider include obesity, liposarcoma, and Cushing's syndrome.

Patient consent obtained.

Meningaud JP, Pitak-Arnnop P, Bertrand JC. Multiple symmetric lipomatosis: case report and review of the literature. J Oral Maxillofac Surg 2007:65:1365-9. 10.1016/j.joms.2005.10.045 17577504

Published by the BMJ Publishing Group Limited. For permission to use (where not already granted under a licence) please go to http://group.bmj.com/group/rights-licensing/ permissions 